\title{
Prenatal Depression Effects and Interventions: A Review
}

\author{
Tiffany Field ${ }^{1,2}$, Miguel Diego ${ }^{1}$, and Maria Hernandez-Reif ${ }^{3}$ \\ 1 Touch Research Institutes, University of Miami Medical School \\ 2 Fielding Graduate University \\ 3 University of Alabama
}

Abstract

This review covers research on the negative effects of prenatal depression and cortisol on fetal growth, prematurity and low birthweight. Although prenatal depression and cortisol were typically measured at around 20 weeks gestation, other research suggests the stability of depression and cortisol levels across pregnancy. Women with Dysthymia as compared to Major Depression Disorder had higher cortisol levels, and their newborns had lower gestational age and birthweight. The cortisol effects in these studies were unfortunately confounded by low serotonin and low dopamine levels which in themselves could contribute to non-optimal pregnancy outcomes. The negative effects of depression and cortisol were also potentially confounded by comorbid anxiety, by demographic factors including younger age, less education and lower SES of the mothers and by the absence of a partner or a partner who was unhappy about the pregnancy or a partner who was depressed. Substance use (especially caffeine use) was still another risk factor. All of these problems including prenatal depression, elevated cortisol, prematurity and low birthweight and even postpartum depression have been reduced by prenatal massage therapy provided by the women's partners. Massage therapy combined with group interpersonal psychotherapy was also effective for reducing depression and cortisol levels. Several limitations of these studies were noted and suggestions for future research included exploring other predictor variables like progesterone/estriol ratios, immune factors and genetic determinants. Further research is needed both on the potential use of cortisol as a screening measure and the use of other therapies that might reduce prenatal depression and cortisol in the women and prematurity and low birthweight in their infants.

\begin{abstract}
Prenatal depression has contributed to prematurity and low birthweight ( $\mathrm{Li}, \mathrm{Liu}, \&$ Odouli, 2009; Marcus, 2009). Some have suggested that high prenatal cortisol levels associated with depression may result in elevated fetal cortisol, delayed fetal growth and prematurity (Van den Bergh Mulder, Mennes \& Glover, 2005) as well as impaired fetal brain development (Weinstock, 2005). Elevated norepinephrine and uterine artery resistance have also been implicated in fetal growth delays (Teixeira, Fisk \& Glover, 1999). Uterine artery resistance would limit uterine blood flow and thereby limit the supply of oxygen and nutrients to the fetus resulting in growth deprivation and shorter gestation (Maina, Saracco, Giolito, Danelon, Bogetto, \& Todros, 2008; Sjostrom, Valentin, Thelin, \& Marsal, 1997).
\end{abstract}

Correspondence and requests for reprints should be sent to Tiffany Field, Ph.D., Touch Research Institute, University of Miami School of Medicine, Department of Pediatrics (D-820), P.O. 016820, Miami, FL, 33101, tfield@med.miami.edu.

Publisher's Disclaimer: This is a PDF file of an unedited manuscript that has been accepted for publication. As a service to our customers we are providing this early version of the manuscript. The manuscript will undergo copyediting, typesetting, and review of the resulting proof before it is published in its final citable form. Please note that during the production process errors may be discovered which could affect the content, and all legal disclaimers that apply to the journal pertain. 


\section{Prenatal Depression Increases Prematurity and Low Birthweight}

Higher cortisol levels in prenatally depressed women have been noted in several samples (see Field \& Diego, 2008 for a review). In addition, depressed women have lower dopamine and serotonin levels and are more likely to deliver prematurely and have low birthweight infants (Field, Diego, Dieter, Hernandez-Reif, Schanberg, Kuhn et al., 2004a). The newborns of the depressed mothers in the Field et al (2004a) study also had higher cortisol levels and lower dopamine and serotonin levels, thus mimicking their mothers' prenatal levels. And, in another study from our lab, the mothers' cortisol levels at 26 weeks accounted for $40 \%$ of the variance in the newborns' cortisol levels (Diego, Field, Hernandez- Reif, Cullen, Schanberg, \& Kuhn, 2004). Also, like their mothers, the newborns of depressed mothers had other signs that have been associated with chronic depression including greater relative right frontal EEG activation and lower vagal activity (Field et al., 2004a). Finally, they received lower scores on the Brazelton Neonatal Behavioral Assessment Scale. A path analysis on the effects of the mothers' prenatal depression and biochemical profile on their newborns' gestational age and birthweight suggested a path from prenatal depression to prenatal cortisol and norepinephrine levels, and, in turn, a path from prenatal cortisol to prematurity and low birthweight. These studies led to the following research including additional mechanism studies.

\section{Prenatal Cortisol Contributes to Fetal Growth Delays and Prematurity}

To further investigate the prenatal cortisol effects, relationships were assessed between the mothers' prenatal depression and biochemistry and fetal activity, fetal growth and neonatal outcomes (Diego, Jones, Field, Hernandez-Reif, Schanberg, Kuhn et al., 2006; Field, Diego, Hernandez-Reif, Gil \& Vera, 2005a; Field, Hernandez-Reif, Diego, Figueiredo, Schanberg, \& Kuhn, 2006c). In these studies, growth measures were taken on fetuses of depressed and non-depressed women during ultrasound sessions at approximately 16 to 20 weeks gestation. On fetal growth measures (estimated weight, femur length, abdominal circumference, biparietal diameter, and head circumference) the fetuses of depressed versus those of non-depressed women showed growth delays (See figure 1). Growth measures, in turn, were inversely related to fetal activity and low birthweight. In addition, $24 \%$ of the fetuses of depressed mothers (versus 7\% of the fetuses of non-depressed mothers) were born prematurely. Prenatal cortisol levels have been notably predictive of preterm birth at an even earlier gestational age (Sandman, Glynn, Dunkel-Shetter, Wadhwa, Garite, Chicz-DeMet, et al., 2006). In that study, cortisol levels were higher at 15 weeks gestation and at 19 weeks gestation in women who later delivered preterm infants.

Others have reported similar relationships between prenatal depression and decreased fetal growth (Hoffman \& Hatch 2000) and between cortisol and shorter gestation by others (Dayan, Creveuil, Marks, Conroy, Herlicoviez, Dreyfus et al., 2006). However, even though approximately $10 \%$ of maternal cortisol is thought to cross the placenta (Gitau, Cameron, Fisk \& Glover, 1998), other data are not definitive (Shea, Streiner, Fleming, Kamath, Broad, $\&$ Steiner, 2007).

\section{Stability of Mood States and Cortisol across Pregnancy}

Cortisol and mood states across pregnancy appear to be stable (from 20 to 32 weeks gestation) and cortisol was related to both depression and anxiety (Field, Hernandez-Reif, \& Diego, 2006a). Significant stability was noted between the 20-week and the 32-week measures including depression, anxiety and cortisol. These were, in turn, correlated with each other and with low back pain, leg pain and sleep disturbances. These data suggested the stability of cortisol, depression and anxiety across pregnancy. A replication was conducted using the CES-D depression scale at every trimester (Field, Diego, Hernandez-Reif, 
Figueiredo, Schanberg, Kuhn et al., 2008e). Chronicity was, again, characteristic of the entire sample.

\section{Sleep Disturbances}

Sleep disturbances were highly correlated with elevated cortisol in the Field et al (2006a) study. Based on animal data, the HPA axis (hypothalamic pituitary adrenal axis) is a potential underlying mechanism for the effects of prenatal depression on sleep problems (Ader, 1975). At least one study has reported a relationship between the diurnal pattern in cortisol and sleeping through the night (de Weerth, van Hees, \& Buitelaar, 2003). We have also noted relationships between prenatal depression, sleep and cortisol levels (Field et al., 2004a) and the confounding effects of prenatal anxiety and anger, as already noted. The pregnant women were then given self-report measures on sleep disturbances (Field, Diego, Hernandez-Reif, Figueiredo, Schanberg, \& Kuhn, 2008d). Their newborns were also observed during sleep. During both the second and third trimesters, the depressed women had more sleep disturbances and higher depression, anxiety and anger scores as well as higher norepinephrine and cortisol levels. The newborns of the depressed mothers also had more sleep disturbances including less time in deep sleep and more time in indeterminate (disorganized) sleep, and they were more active and cried/fussed more. Others have similarly reported more sleep disturbance in infants of depressed mothers (O'connor, Caprariello, Blackmore, Gregory, Glover, \& Fleming, 2007).

\section{Dysthymia versus Major Depression Disorder Effects}

Comparing Dysthymia versus Major Depression Disorder effects was another way to assess chronic depression effects. To determine differences between pregnant women with Dysthymia versus Major Depression, the depressed pregnant women were divided by their diagnoses on the Structured Clinical Interview for DSM IV Diagnoses into Dysthymic and Major Depression Disorder groups, and they were compared on self-report measures (depression, anxiety, anger, daily hassles and behavioral inhibition), on cortisol levels, and on fetal measurements (Field, Diego, Hernandez-Reif, Figueiredo, Ascencio, Schanberg et al., 2007a). The Major Depression Disorder group had more self-reported symptoms. However, the Dysthymic group had higher prenatal cortisol levels and lower fetal growth measurements (estimated weight, femur length and abdominal circumference) as measured at their first ultrasound ( $M=18$ weeks gestation). Thus, depressed pregnant women with Dysthymia and Major Depression appeared to have different prenatal symptoms, and the outcome appeared to be worse for the Dysthymia (chronic depression) group.

The depressed pregnant women classified as Dysthymic or Major Depression Disorder were then followed to the newborn period (Field, Diego, \& Hernandez-Reif, 2008a). The newborns of Dysthymic versus Major Depression Disorder mothers had a significantly lower gestational age, a lower birthweight, shorter birth length and less optimal obstetric complications scores. The neonates of dysthymic mothers also had lower orientation and motor scores and more depressive symptoms on the Brazelton Neonatal Behavioral Assessment Scale. These findings were not surprising given the elevated cortisol levels and the inferior fetal measures including lower weight, length, femur length and abdominal circumference noted in our earlier study on fetuses of dysthymic pregnant women (Field et al., 2007a).

Thus, elevated prenatal cortisol has been associated with several negative conditions including excessive fetal activity, delayed fetal growth, prematurity and low birthweight (See Field \& Diego, 2008 for a review; Obel, Hedegaard, Henriksen, Secher, Olsen, \& Levine, 2005). Others have also reported relationships between prenatal cortisol and attention and temperament problems in later infancy, externalizing problems in childhood, 
and psychopathology and chronic illness in adulthood (Brennan, Parages, Walker, Green, Newport, \& Stowe, 2008; Davis, Glynn, Schetter, Hobel, Chicz-Demet, \& Sandman 2007; Deave, Heron, Evans, \& Edmond, 2008; Phillips, 2007; Weinstock, 2005). Given that maternal prenatal cortisol crosses the placenta and influences other aspects of the prenatal environment (Glover, Teixeira, Gitau, \& Fisk, 1999), these effects on the fetus and later development are not surprising. Cortisol would appear to be a mediating variable, resulting from prenatal stress that takes several forms including depression, anxiety, anger and daily hassles. Cortisol effects have been confounded by the effects of other neurotransmitters such as serotonin, dopamine and norepinephrine. Norepinephrine, for example, may itself cause premature birth via intrauterine growth deprivation deriving from uterine artery resistance (Glover et al, 1999).

Cortisol also interacts with other systems. Numerous data, for example, have suggested reciprocal interactions between the serotonin system and the hypothalamic-pituitary-adrenal axis (cortisol levels) (Kitamura, Araki, \& Gomita, 2002; McAllister-Williams, Ferrier, \& Young, 1998). Dysfunctional interactions between serotonin and cortisol and between serotonin and dopamine have also been reported (Esposito, 2006; Kalia, 2005; Trivedi, 2006). In addition, we have noted interactions including lower serotonin and dopamine levels and higher cortisol levels, as already mentioned in our earlier study on depressed pregnant women (Field et al., 2004a). In that study, the biochemical profiles of prenatally depressed women predicted similar profiles in their neonates.

\section{Prenatal Dopamine Effects}

In a study on the effects of prenatal dopamine, depressed pregnant women were divided into high and low prenatal maternal dopamine (HVA) groups based on a tertile split on their dopamine levels at 20 weeks gestation (Field, Diego, Hernandez-Reif, Figueiredo, Deeds, Ascencio et al., 2008b). The high versus the low dopamine group had lower CES-D scores and higher norepinephrine levels at the 20 week gestational age assessment and higher dopamine and serotonin levels at both the 20 and the 32 week gestational age assessments. The neonates of the mothers with high versus low prenatal dopamine levels also had higher dopamine and serotonin levels as well as lower cortisol levels. Finally, the neonates in the high dopamine group had better autonomic stability and excitability scores on the Brazelton Neonatal Behavior Assessment Scale. Thus, prenatal maternal dopamine levels appear to be negatively related to prenatal depression scores and positively related to neonatal dopamine and behavioral regulation, although these effects were confounded by elevated serotonin levels.

\section{Prenatal Serotonin Effects}

Serotonin has long been associated with depression (Cubala \& Landwski, 2006; Neumeister, 2003; Neumeister, Young, \& Stastny, 2004). Serotonin receptors and serotonin transporters are reduced in depression, suggesting that serotonin systems play a key role in the pathophysiology of depression (Neumeister et al., 2004).

In a study on relationships between prenatal serotonin levels and other biochemical variables during pregnancy as well as their relationships to neonatal biochemical and behavioral variables, pregnant women were divided into the top and bottom tertiles based on their serotonin levels at 20 weeks gestational age (Field, Diego, Hernandez-Reif, Figueiredo, Deeds, Ascencio et al., 2007b). The reciprocal relationships often noted between serotonin and dopamine and serotonin and cortisol were surprisingly not evident for the neonates in this sample. That the incidence of prematurity in the low serotonin group was twice the rate in the high serotonin group suggests that low serotonin levels, like elevated cortisol, may be a marker for preterm delivery. 
These data highlight the importance of monitoring serotonin levels during prenatal assessments. Urine samples collected at prenatal clinics could be assayed for serotonin, dopamine and cortisol levels, as they may help identify women at risk for premature delivery. In addition, the CES-D scores, and especially the somatic-vegetative subscale scores on the CES-D, appear to be elevated in women with low prenatal serotonin levels. These may be cost-effective screening measures for targeting those women needing prenatal interventions, especially since they seem to have some predictive validity from as early as 20 weeks gestation, which may not be too late for intervention. Future studies would need to be conducted on larger samples to assess the validity of these screening measures.

\section{Comorbid Depression and Anxiety Effects}

Anxiety is often comorbid with depression, making it difficult to assess the independent effects of either depression or anxiety (Beuke, Fisher, \& Mc Dowall, 2003). This comorbidity is not surprising given that depression and anxiety are thought to share a common genetic pathway (Kendler, Gardner, Gatz, \& Pedersen, 2007; Williamson, Forbes, Dahl, \& Ryan, 2005). Because depressed pregnant women have also been noted to experience high anxiety (Dieter et al.,, 2001; Hoffman \& Hatch 2000; Lundy, Jones, Field, Nearing, Davalos, Pietro, et al., 1999), we assessed the combined effects of anxiety and depression. In this study, the effects of comorbid depression and anxiety were compared to the effects of depression alone and anxiety alone on pregnancy mood states and biochemistry and on neonatal outcomes in a large multi-ethnic sample (Field, Diego, Hernandez-Reif, Figueiredo, Deeds, Ascencio et al., 2008c). The comorbid group (based on SCID depression and anxiety disorder diagnoses) had higher scores than the other groups on self-report measures of depression, anxiety, anger and daily hassles, and they had lower dopamine levels. As compared to the non-depressed group, they also reported more sleep disturbances and relationship problems. And, finally, the comorbid group also experienced a greater incidence of prematurity. However, they did not differ from the other disorder groups on being lower birthweight and lower birth length than the non-depressed group. Also, they did not differ from the depressed group on having higher cortisol and norepinephrine and lower dopamine and serotonin levels than the other groups and on having greater relative right frontal EEG than the other groups. These data suggest that for some measures, and for predicting prematurity, comorbid depression and anxiety was the highest risk condition. On other variables, comorbidity was no more impactful than depression alone.

\section{Demographic Risk Factors}

Because demographic risk factors emerged in our studies, we combined several predominantly Hispanic samples and explored multiple risk factors (Field, Hernandez-Reif, \& Diego, 2006b). The women were diagnosed as depressed based on the Center for Epidemiological Studies Depression Scale (CES-D) and the Structured Clinical Interview for DSM IV Diagnoses (SCID). They were interviewed on several demographic risk factors and stress questionnaires. On average, the depressed pregnant women were younger, they had lower education levels and lower socioeconomic status, and they were less often married. Fewer of the depressed women and their partners were happy when they were told that they were pregnant, a greater number of the depressed women experienced a stressful situation during pregnancy, more of the depressed women were prescribed antibiotics during pregnancy, and the depressed women had less optimal obstetric complications scores, including a greater incidence of prematurity. Finally, the scores of the depressed pregnant women on the stress questionnaires suggested greater depression (CES-D), anxiety (STAI), anger (STAXI), pregnancy anxieties (PAAS) and daily hassles. Several of these 
psychosocial risk factors have been noted by others (Bunevicius, R., Kusminskas, Bunevicius, A., Nadisauskiene, Jureniene, \& Pop, 2009).

Black women have the highest prematurity rate. In a meta-analysis of a larger database, preterm births occurred in $9.7 \%$ of U.S. singleton births (Raegan \& Salsberry, 2005). The rate for black women was double that of white women, and the rate was $25 \%$ higher for black than for Hispanic women. These authors suggested that while a number of individual correlates with preterm birth have been identified, race and ethnic differences have not been fully explained. Thus, the negative birth outcomes of low birthweight and preterm delivery have been disproportionately reported for black women, and these ethnic disparities in negative pregnancy outcomes have been relatively unchanged for decades (Zayas, Cunningham, McKee, \& Jankowski, 2002). However, very little information exists to explain these disparities (Stewart, Dean, Gregorich, Brawarsky, \& Haas, 2007). We therefore studied risk factors in a black sample (Field, Diego, Hernandez-Reif, Deeds, Holder, Schanberg et al., 2009c). The comparison of black depressed pregnant women to black non-depressed pregnant women yielded non-optimal results for the depressed black women that were similar to those from predominantly Hispanic samples (Field et al., 2006b; Zayas \& Busch-Rossnagel, 1992). The depressed women had higher anxiety, anger, daily hassles and sleep disturbance scores and greater increases in cortisol levels across pregnancy which, in turn, contributed to a greater incidence of prematurity and low birthweight. These results could again be attributed to the greater depression in black women (Branch, 2002; Cunningham \& Zayas, 2002).

\section{Substance Use As A Risk Factor}

Although rates of smoking, drinking and drug use during pregnancy have been relatively low (Marcus, Flynn, Blow, \& Barry, 2003; Orr, Blazer, James, \& Reiter, 2007), some prenatal studies have reported relationships between these risk factors and negative neonatal outcomes independent of prenatal depression (Dole, Savitz, Siega-Riz, Hertz-Picciotto, McMahon, \& Buekens, 2004; Monk, Sloan, Myers, Ellman, Werner, Jeon et al., 2004). In a study on substance use as a risk factor, depressed pregnant women reported more substance use including cigarettes, caffeine and medications (primarily antibiotics) (Field, Yando, Bendell, Hernandez-Reif, Diego, Vera et al., 2007c). Their scores on the Feelings about Pregnancy and Delivery Scale were lower including the coping, support, intimacy, and cultural effects subscale scores. In addition, they reported having more stressful situations during pregnancy, being less happy when finding out they were pregnant, and their significant others were reportedly less happy when finding out about the pregnancy. Others have similarly suggested the problem of misinterpreting the symptoms of depression (sleep problems, energy and appetite changes) as normative experiences of pregnancy rather than depression (Marcus, 2009).

In this review, additional complications of pregnancy that are associated with depression were noted including inadequate weight gain, under-utilization of prenatal care, poor health, lower SES and alcohol use. In addition, prenatal smoking has led to reduced birthweight and later antisocial behaviors (Rice, Harold, Bolvin, Hay, Van den Bree, \& Thapar, 2009), and cocaine, among other illicit drugs, has significantly negative effects on neonatal outcomes (Eisen, Field, Bandstra, Roberts, Morrow, Larson et al., 1991; Scafidi, Field, Wheeden, Schanberg, Kuhn, Symanski et al., 1996). Caffeine use has also affected neonatal outcomes (Diego et al., 2007). Newborns of mothers who consumed caffeine (62\% of mothers drank caffeine daily) were more often low birthweight and showed more stress behaviors. Even psychotropic medications have been noted to affect the fetus (see Field, 2010 for a review; Emory \& Dieter, 2006). 


\section{Paternal Depression As A Risk Factor}

Paternal depression was an additional risk factor in at least one study on the effects of paternal depression on prenatal depression symptoms, anxiety, anger and daily hassles in depressed and non-depressed pregnant women and their depressed and non-depressed partners (fathers-to-be) (Field, Diego, Hernandez-Reif, Figueiredo, Deeds, Contogeorgos et al., 2006d). Depressed versus non-depressed fathers had higher depression, anxiety and daily hassles scores. Although the pregnant women in general had lower anxiety, anger and daily hassles scores than the men, the depressed fathers and depressed mothers' scores did not differ. Paternal depression also had less effect than maternal depression on their partners' scores. However, the similarity between the scores of depressed mothers and depressed fathers highlights the importance of screening for depression in fathers-to-be as well as mothers-to-be during pregnancy.

\section{Massage Therapy Reduces Prenatal Depression and Cortisol and Improves Neonatal Outcomes}

Various forms of stimulation have been noted to lower prenatal depression and cortisol including yoga (Narendran, S., Nagarathna, Narendran, V., Gunasheela, \& Nagendra, 2005) and massage therapy (Field, Diego, Hernandez-Reif, Schanberg, \& Kuhn, 2004b). And, serotonin and dopamine are increased following massage therapy (Field, Hernandez-Reif, Diego, Schanberg, \& Kuhn, 2005c) and after exercise (Struder, Hollmann, Platen, Wostmann, Ferrauti, \& Weber, 1997). Thus, with these cost-effective interventions, the costly problems of prematurity may be reduced. Knowing that prenatal depression (and elevated cortisol) contributed to prematurity, we conducted a pregnancy massage study that effectively reduced prenatal depression, cortisol and prematurity (Field, et al, 2004b). The results of that study led to the following studies.

Vagal activity has been notably lower in depressed pregnant women and in their newborns (Field et al 2004a; Jones, Field, Fox, Davalos, Lundy, \& Hart, 1998). Low vagal activity is related to several developmental problems including behavior problems in later childhood (Porges, Doussard-Roosevelt, Portales, \& Greenspan, 1996). To explore the possibility that the massage therapy effects were mediated by increased vagal activity, we conducted a study on moderate versus light pressure massage (Diego \& Field, 2008). As can be seen in figure 2, vagal activity increased (a positive effect) following moderate pressure massage, but not following light pressure massage. The stimulation of pressure receptors appears to increase vagal activity which in turn would reduce cortisol levels.

Because we had shown that partners could effectively provide pregnancy massage (Field et al., 2004b), we repeated the study using partners as therapists. In this study we also assessed the effects on the partners. Prenatally depressed women were randomly assigned to a control group or a group that received massage twice weekly from their partners from 20 weeks gestation until the end of pregnancy (Field, Figueiredo, Hernandez-Reif, Diego, Deeds, \& Ascencio, 2008f). Self-reported leg pain, back pain, depression, anxiety and anger decreased more for the massaged pregnant women than for the control group women. In addition, the partners who massaged the pregnant women versus the control group partners reported less depressed mood, anxiety and anger across the course of the massage therapy period. Finally, scores on a relationship questionnaire that we developed for this study improved more for both the women and the partners in the massage group (Figueiredo, Field, Diego, Hernandez-Reif, Deeds, \& Ascencio, 2008). These data suggest that not only mood states but also relationships improved when depressed pregnant women were massaged by their partners. This finding on the fathers/partners benefiting from giving massage was also noted in another study but in a higher socioeconomic status sample (Latifses, Bendell, Estroff, 
Field, \& Bush, 2005). In that study, the partners who massaged the women across pregnancy had lower anxiety and better relationships.

In a longer-term study using partners as therapists, pregnant women diagnosed with major depression were provided twelve weeks of twice per week massage therapy by their significant other or received standard treatment as a control group (Field, Diego, HernandezReif, Deeds \& Figueiredo, 2009b). The therapy group women versus the control group women not only had reduced depression and cortisol by the end of the therapy period, but they also had reduced depression during the postpartum period. Their newborns were also less likely to be born prematurely and low birthweight, and they had lower cortisol levels and performed better on the Brazelton Neonatal Behavioral Assessment habituation, orientation and motor scales.

Neonates born to depressed mothers benefited even more when their mothers received moderate pressure massage versus light pressure massage during pregnancy. The newborns were compared on their behaviors during 15-minute sleep- wake behavior observations and on their performance on the Brazelton Neonatal Behavior Assessment Scale (Field, Hernandez-Reif, \& Diego, 2005b). The group of neonates whose mothers received moderate pressure massage spent a greater percent of the observation time smiling and vocalizing, and they received better scores on the orientation, motor, excitability and depression clusters on the Brazelton scale.

To determine whether massage therapy would facilitate compliance with psychotherapy, pregnant women who were diagnosed depressed were randomly assigned to a group who received group interpersonal psychotherapy or to a group who received both group interpersonal psychotherapy and massage therapy (Field, Deeds, Diego, Gauler, Sullivan, Wilson et al., 2009a). The group interpersonal psychotherapy (one hour sessions) and massage therapy (30 minute sessions) were held once per week for six weeks. The group therapy process appeared to be effective for both groups, as suggested by the increased expression of both positive and negative affect and increased relatedness during the group therapy sessions. The group who received psychotherapy plus massage attended more psychotherapy sessions on average, and a greater percentage of that group completed the six-week program. The group who received both therapies also showed a greater decrease on the depression summary scores and on the depressed affect and somatic-vegetative symptoms subscale scores on the Center for Epidemiological Studies Depression Scale (CES-D). They also had a greater decrease in anxiety scores on the State Anxiety Inventory (STAI) and a greater decrease in cortisol levels. Thus, the data highlight the facilitative effects of massage therapy on group interpersonal psychotherapy for reducing prenatal depression.

\section{Limitations of These Studies}

Several Limitations of these studies should be noted. First, the samples were not representative of women who seek treatment including psychotherapy and antidepressants. Less than 3\% of our prenatal clinic population was in treatment, which is consistent with the incidence of psychiatric treatment in other samples of depressed pregnant women (Flynn, Blow, \& Marcus, 2006; Suri, Althshuler, Hellemann, Burt, Aquino, \& Mintz, 2007). Notably, antidepressants have their own negative effects (see Chambers, Moses-Kolko, \& Weisner, 2007; Field, 2010 for reviews). These studies were also limited to lower socioeconomic status women who, of course, have many other problems in addition to their depression, as was noted in our study on multiple risk factors (Field et al, 2006b).

Another limitation was that other comorbid risk factors like anxiety and anger were not assessed in all of the studies. In the studies that assessed comorbidity, the women with 
comorbid depression and anxiety fared worse (Field et al., 2008c) and, of course, the comorbid condition is more common than prenatal depression alone (Hoffman \& Hatch, 2000).

In addition, the assessments were limited to 2 time periods during pregnancy (16-20 weeks gestation and 30-34 weeks gestation), and different gestational age fetuses may, of course, be differentially affected (Martin \& Dombrowski, 2008). It is, however, difficult to recruit younger gestational age women because they typically do not attend prenatal clinics at an earlier age, and late in gestation they are often delivering prematurely.

Our continuing focus on cortisol as a potential predictor is also limited. Although we have elsewhere referred to cortisol as the "culprit variable" (see Field \& Diego, 2008 for a review), several other variables have been explored and need further explanation including uterine artery resistance (Copper, Goldenberg, Das, Elder, Swain, Norman et al.,1996; Tchirikov, Rybakowski, Huneke, Schoder, \& Schroder, 2002; Van den Bergh et al, 2005), and other biochemical markers including norepinephirine (Lundy et al., 1999), progesterone and estriol. For example progesterone/estriol ratios are also predictive of prematurity (Ruiz, Saade, Brown, Nelson-Becker, Tan, Bishop et al., 2008). But it is not clear how they compare to cortisol as predictors.

Immune factors have also been implicated in both depression (Suarez, Lewis, Krishnan, \& Young, 2004; Zorrilla, Luporsky, McKay, Rosenthal, Houldin, Tax et al., 2001) and in prematurity (Keelan, Marvin, Sato, Coleman, McCowan, \& Mitchell, 1999). These immune models have implicated elevated pro-inflammatory cytokines (most especially IL-1, IL-6, and TNF- alpha) and low levels of natural killer cell activity in depression. These models have not yet been explored in prenatal depression.

Others (Wust, Federenko, van Rossum, Koper, \& Hellhammer, 2005) have suggested that genetic determinants could mediate the relationship between HPAC activity (cortisol) and low birthweight or short gestational age inasmuch as twin studies have shown high heritability of HPAC activity (Bartels, Van den Berg, Sluyter, Boomsa, \& de Geus, 2003; Federenko, Nagamine, Hellhammer, Wadhwa, \& Wust, 2004; Wust, Federenko, Hellhammer, \& Kirschbaum, 2000). In this way, according to the authors, genetic factors may influence the cortisol levels that the fetus is exposed to and their impact on birthweight, length and gestational age.

Lastly, developmental follow-ups are needed to determine any lasting effects of prenatal depression. If the depression is chronic, one might expect that the prenatal depression effects would be compounded by the postpartum depression effects that have been reported into late childhood (Hay, Pawlby, Angold, Harold, \& Sharp, 2003). Other prenatal depression effects may only emerge later in development (Dombrowski, Noonan, \& Martin, 2007).

\section{Summary}

In summary, this review highlights the negative effects of prenatal depression and cortisol on fetal growth, prematurity and low birthweight. The stability of depression and cortisol levels across pregnancy highlighted the chronicity of prenatal depression. The finding that women with Dysthymia as opposed to Major Depression Disorder had the highest cortisol levels and that their newborns had lower gestational age and birthweight suggests that chronic prenatal depression had the most negative effects. The cortisol effects unfortunately were confounded by low serotonin and low dopamine levels which in themselves could contribute to non-optimal pregnancy outcomes. Other potentially confounding effects were comorbid anxiety levels and demographic factors including younger age, less education and lower SES of the women as well as the absence of a partner, a partner who is unhappy about 
the pregnancy or a partner who is depressed. Substance use including alcohol, smoking and even caffeine use were still other risk factors. All of these problems including prenatal depression, cortisol levels, prematurity and low birthweight and even postpartum depression have been reduced by massage therapy provided by the women's partner. Massage therapy combined with group interpersonal psychotherapy was also effective for reducing depression and cortisol levels. Several limitations of these studies were noted, and suggestions for future research included exploring other predictor variables like progesterone/estriol ratios, immune factors and genetic determinants. Further research is needed on the potential use of cortisol as a screening measure and the use of other therapies that might reduce prenatal depression and cortisol as well as prematurity and low birthweight outcomes.

\section{Acknowledgments}

We would like to thank the mothers, fathers and infants who participated in our studies which were supported by NIH Senior Research Scientist Awards (\# MH 00331 and \# AT 01585) and an NIMH Merit award (MH \# 46586) and March of Dimes grant (\#12-FY03-48) to Tiffany Field and funding from Johnson and Johnson Pediatric Institute.

\section{References}

Ader R. Neonatal stimulation and maturation of the 24-hour adrenocortical rhythm. Progress in brain research, hormones, homeostasis and the brain 1975;42:333-341.

Bartels M, Van den Berg M, Sluyter F, Boomsma D, de Geus E. Heritability of cortisol levels: review and simultaneous analysis of twin studies. Psychoneuroendocrinology 2003;28:121-137. [PubMed: 12510008]

Beuke CJ, Fisher R, McDowall J. Anxiety and depression: Why and how to measure their separate effects. Clinical Psychology Review 2003;23:831-848. [PubMed: 14529700]

Branch RC. The intersection of mental health, pregnancy and race: A contextual investigation of the relationships between social factors and maternal psychological distress. Dissertation Abstracts International Section A: Humanities and Social Sciences 2002;62:2583.

Brennan PA, Parages R, Walker EF, Green P, Newport DJ, Stowe Z. Maternal depression and infant cortisol: influences of timing, comorbidity and treatment. Journal of Child Psychology and Psychiatry 2008;49:1099-1107. [PubMed: 18492036]

Bunevicius R, Kusminskas L, Bunevicius A, Nadisauskiene RJ, Jureniene K, Pop VJ. Psychosoical risk factors for depression during pregnancy. Acta Obstetricia et Gynecologica Scandinavica 2009;88:599-605. [PubMed: 19308810]

Chambers C, Moses-Kolko E, Wisner KL. Antidepressant use in pregnancy: new concerns, old dilemmas. Expert Review of Neurotherapeutics 2007;7:761-764. [PubMed: 17610382]

Copper RL, Goldenberg RL, Das A, Elder N, Swain M, Norman G, ...Bottoms SF. The preterm prediction study: maternal stress is associated with spontaneous preterm birth at less than thirty-five weeks' gestation. National Institute of Child Health and Huiman Development Maternal-Fetal Medicine Units Network. American Journal of Obstetrics \& Gynecology 1996;175:1286-1292. [PubMed: 8942502]

Cubala W, Landwiski J. Serotonergic system and limbic-hypothalamic-pituitary-adrenal axis (LHPA axis) in depression. Psychiatry Polska 2006;40:415-430.

Cunningham M, Zayas LH. Reducing depression in pregnancy: Designing multimodal interventions. Social Work 2002;47:114-123. [PubMed: 12019798]

Davis EP, Glynn LM, Schetter CD, Hobel C, Chicz-Demet A, Sandman CA. Prenatal exposure to maternal depression and cortisol influences infant temperament. Journal of America Academy of Child \& Adolescent Psychiatry 2007;46:737-746.

Dayan J, Creveuil C, Marks MN, Conroy S, Herlicoviez M, Dreyfus M, Tordjman S. Prenatal Depression, Prenatal Anxiety, and Spontaneous Preterm Birth: A Prospective Cohort Study among Women with Early and Regular Care. Psychosomatic Medicine 2006;6:938-946. [PubMed: 17079701] 
de Weerth C, van Hees Y, Buitelaar JK. Prenatal maternal cortisol levels and infant behavior during the first 5 months. Early Human Development 2003;74:139-151. [PubMed: 14580753]

Deave T, Heron J, Evans J, Emond A. The impact of maternal depression in pregnancy on early child development. International Journal of Obstetrics \& Gynecology 2008;115:1043-1051.

Diego MA, Field T, Hernandez- Reif M, Cullen C, Schanberg S, Kuhn C. Prepartum, postpartum, and chronic depression effects on newborns. Psychiatry: Interpersonal and Biological Processes 2004;1:63-80.

Diego M, Field T. Moderate pressure massage elicits a parasympathetic nervous system response. International Journal of Neuroscience 2008;119:630-638. [PubMed: 19283590]

Diego MA, Jones NA, Field T, Hernandez-Reif M, Schanberg S, Kuhn C, Gonzalez-Garcia A. Maternal psychological distress, prenatal cortisol and fetal weight. Psychosomatic Medicine 2006;68:747-53. [PubMed: 17012528]

Diego M, Field T, Hernandez-Reif M, Vera Y, Gil K, Gonzalez-Garcia A. Caffeine use affects pregnancy outcome. Journal of Child \& Adolescent Substance Abuse 2007;17:41-48.

Dieter JN, Field T, Hernandez-Reif M, Jones NA, Lecanuet JP, Salman FA, Redzepi M. Maternal depression and increased fetal activity. Journal of Obstetrics Gynaecology 2001;5:468-473.

Dole N, Savitz DA, Siega-Riz AM, Hertz-Picciotto I, McMahon MJ, Buekens P. Psychosocial factors and preterm birth among African Americans and White women in central North Carolina. American Journal of Public Health 2004;8:1358-1365. [PubMed: 15284044]

Dombrowski SC, Noonn K, Martin RP. Low birth weight and cognitive outcomes: Evidence for a gradient relationship in urban, poor, African American birth cohort. School Psychology Quarterly 2007;22:26-43.

Eisen LN, Field TM, Bandstra ES, Roberts JP, Morrow C, Larson SK, Steele B. Perinatal cocaine effects on neonatal stress behavior and performance on the Brazelton scale. Pediatrics 1991;88:477-480. [PubMed: 1881726]

Emory EK, Dieter JN. Maternal depression and psychotropic medication effects on the human fetus. Annals of the New York Academy of Sciences 2006;1094:287-291. [PubMed: 17347363]

Esposito E. Serotonin-dopamine interaction as a focus of novel antidepressant drugs. Current Drug Targets 2006;7:177-185. [PubMed: 16475959]

Federenko I, Nagamine M, Hellhammer D, Wadhwa P, Wust S. The heritability of hypothalamus pituitary adrenal axis responses to psychosocial stress is context dependent. Journal of Clinical Endocrinology and Metabolism 2004;89:6244-6250. [PubMed: 15579784]

Field T. Prenatal depression and selective serotonin reuptake inhibitors. International Journal of Neuroscience 2010;120:163-167. [PubMed: 20374082]

Field T, Deeds O, Diego M, Gauler A, Sullivan S, Wilson D, Nearing G. Benefits of combining massage therapy with group interpersonal psychotherapy facilitated treatment compliance and lowered stress hormones in prenatally depressed women. Journal of Bodywork and Movement Therapies 2009a;13:297-303. [PubMed: 19761951]

Field T, Diego M. Cortisol: The culprit prenatal stress variable. International Journal of Neuroscience 2008;118:1181-1205. [PubMed: 18589921]

Field T, Diego M, Dieter J, Hernandez-Reif M, Schanberg S, Kuhn C, Bendell D. Prenatal depression effects on the fetus and the newborn. Infant Behavior \& Development 2004a;27:216-229.

Field T, Diego M, Hernandez-Reif M. Prenatal dysthymia versus major depression effects on the neonate. Infant Behavior and Development 2008a;31:190-193. [PubMed: 18037494]

Field T, Diego M, Hernandez-Reif M, Deeds O, Figueiredo B. Pregnancy massage reduces prematurity, low birthweight and postpartum depression. Infant Behavior and Development 2009b; 32:454-460. [PubMed: 19646762]

Field T, Diego M, Hernandez-Reif M, Deeds O, Holder V, Schanberg S, Kuhn C. Depressed pregnant black women have a greater incidence of prematurity and low birthweight outcomes. Infant Behavior \& Development 2009c;32:10-16. [PubMed: 19004502]

Field T, Diego M, Hernandez-Reif M, Figueiredo B, Ascencio A, Schanberg S, Kuhn C. Prenatal dysthymia versus major depression disorder effects on maternal cortisol and fetal growth. Depression and Anxiety 2007a;25:11-16. 
Field T, Diego M, Hernandez-Reif M, Figueiredo B, Deeds O, Ascencio A, Schanberg S, Kuhn C. Prenatal dopamine and neonatal behavior and biochemistry. Infant Behavior and Development 2008b;31:590-593. [PubMed: 18774177]

Field T, Diego M, Hernandez-Reif M, Figueiredo B, Deeds O, Ascencio A, Schanberg S, Kuhn C. Prenatal serotonin and neonatal outcome. Infant Behavior and Development 2007b;31:316-320. [PubMed: 18279966]

Field T, Diego M, Hernandez-Reif M, Figueiredo B, Deeds O, Ascencio A, Schanberg S, Kuhn C. Comorbid depression and anxiety effects on pregnancy and neonatal outcome. Journal of Affective Disorders 2008c;33:23-29.

Field T, Diego M, Hernandez-Reif M, Figueiredo B, Deeds O, Contogeorgos J, Ascencio A. Prenatal paternal depression. Infant Behavior and Development 2006d;29:579-583. [PubMed: 17138311]

Field T, Diego M, Hernandez-Reif M, Figueiredo B, Schanberg S, Kuhn C. Sleep disturbances in depressed pregnant women and their newborns. Infant Behavior and Development 2008d;30:127133. [PubMed: 17292785]

Field T, Diego M, Hernandez-Reif M, Figueiredo B, Schanberg S, Kuhn C, ...Ascencio A. Chronic prenatal depression and neonatal outcome. International Journal of Neuroscience 2008e;118:95103. [PubMed: 18041608]

Field T, Diego M, Hernandez-Reif M, Gil K, Vera Y. Prenatal maternal cortisol, fetal activity and growth. International Journal of Neuroscience 2005a;115:423-9. [PubMed: 15825247]

Field T, Diego M, Hernandez-Reif M, Schanberg S, Kuhn C. Massage therapy effects on depressed pregnant women. Journal of Psychosomatic Obstetrics \& Gynecology 2004b;25:115-22. [PubMed: 15715034]

Field T, Figueiredo B, Hernandez-Reif, Diego M, Deeds O, Ascencio A. Massage therapy reduces pain in pregnant women, alleviates prenatal depression in both parents and improves their relationships. Journal of Bodywork and Movement Therapies 2008f;12:146-150. [PubMed: 19083666]

Field T, Hernandez-Reif M, Diego M. Newborns of depressed mothers who received moderate versus light pressure massage during pregnancy. Infant Behavior and Development 2005b;29:54-58. [PubMed: 17138261]

Field T, Hernandez-Reif M, Diego M. Stability of mood states and biochemistry across pregnancy. Infant Behavior and Development 2006a;29:262-67. [PubMed: 17138281]

Field T, Hernandez-Reif M, Diego M. Risk factors and stress variables that differentiate depressed from non-depressed pregnant women. Infant Behavior and Development 2006b;29:169-175. [PubMed: 17138272]

Field T, Hernandez-Reif M, Diego M, Figueiredo B, Schanberg S, Kuhn C. Prenatal cortisol, prematurity and low birthweight. Infant Behavior and Development 2006c;29:268-75. [PubMed: 17138282]

Field T, Hernandez-Reif M, Diego M, Schanberg S, Kuhn C. Cortisol decreases and serotonin and dopamine increase following massage therapy. International Journal of Neuroscience 2005c; 115:1397-1413. [PubMed: 16162447]

Field T, Yando R, Bendell D, Hernandez-Reif M, Diego M, Vera Y, Gil K. Prenatal depression effects on pregnancy feelings and substance use. Journal of Child \& Adolescent Substance Abuse 2007c; 17:111-122.

Figueiredo B, Field T, Diego M, Hernandez-Reif M, Deeds O, Ascencio A. Partner relationships during the transition to parenthood. Journal of Reproductive and Infant Psychology 2008;23:99107.

Flynn HA, Blow FC, Marcus SM. Rates and predictors of depression treatment among pregnant women in hospital-affiliated obstetrics practices. General Hospital Psychiatry 2006;4:289-295. [PubMed: 16814627]

Gitau R, Cameron A, Fisk N, Glover V. Fetal exposure to maternal cortisol. The Lancet 1998;352:707-708.

Glover V, Teixeira J, Gitau R, Fisk NM. Mechanisms by which maternal mood in pregnancy may affect the fetus. Contemporary Reviews in Obstetrics and Gynecology 1999;11:155-160. 
Hay DF, Pawlby S, Angold A, Harold GT, Sharp D. Pathways to violence in the children of mothers who were depressed postpartum. Developmental Psychology 2003;39:1083-1094. [PubMed: 14584986]

Hoffman S, Hatch MC. Depressive symptomatology during pregnancy: evidence for an association with decreased fetal growth in pregnancies of lower social class women. Health Psychology 2000;6:535-543. [PubMed: 11129356]

Jones NA, Field T, Fox NA, Davalos M, Lundy BL, Hart S. Newborns of mothers with depressive symptoms are physiologically less developed. Infant Behavior \& Development 1998;3:537-541.

Kalia M. Neurobiological basis of depression: An update. Metabolism 2005;54:24-27. [PubMed: 15877309]

Keelan JA, Marvin KW, Sato TA, Coleman M, McCowan LM, Mitchell MD. Cytokine abundance in placental tissues: evidence of inflammatory activation in gestation membranes with term and preterm parturition. American Journal of Obstetrics and Gynecology 1999;181:1530-1536. [PubMed: 10601939]

Kendler KS, Gardner CO, Gatz M, Pederson NL. The sources of comorbidity between major depression and generalized anxiety disorder in a Swedish national twin sample. Psychological Medicine 2007;3:453-462. [PubMed: 17121688]

Kitamura Y, Araki H, Gomita Y. Interaction of 5HT and HPA axis in depression and treatmentresistant depression. Nippo Yakurigaku Zasshi 2002;119:319-325.

Latifses V, Bendell D, Estroff T, Field T, Bush J. Fathers massaging and relaxing their pregnant wives lowered anxiety and facilitated marital adjustment. Journal of Bodywork and Movement Therapies 2005;9:277-82.

Li D, Liu L, Odouli R. Presence of depressive symptoms during early pregnancy and the risk of preterm delivery: A prospective cohort study. Human Reproduction 2009;24:146-153. [PubMed: 18948314]

Lundy BL, Jones NA, Field T, Nearing G, Davalos M, Pietro PA, Kuhn C. Prenatal depression effects on neonates. Infant Behavior \& Development 1999;1:119-129.

Maina G, Saracco P, Giolito MR, Danelon D, Bogetto F, Todros T. Impact of maternal psychological distress on fetal weight, prematurity and intrauterine growth retardation. Journal of Affective Disorders 2008;111:214-220. [PubMed: 18394713]

Marcus SM. Depression during pregnancy: rates, risks and consequences- mother risk update 2008. The Canadian Journal of Clinical Pharmacology 2009;16:15-22.

Marcus SM, Flynn HA, Blow FC, Barry KL. Depressive Symptoms among Pregnant Women Screened in Obstetrics Settings. Journal of Women's Health 2003;4:373-380.

Martin, RP.; Dombrowski, SC. Prenatal exposures: Psychological and educational consequences for children. NY: Springer; 2008.

McAllister-Williams R, Ferrier I, Young A. Mood and neuropsychological function in depression: The role of corticosteroids and serotonin. Psychological Medicine 1998;28:537-584.

Monk C, Sloan RP, Myers MM, Ellman L, Werner E, Jeon J, Fifer WP. Fetal heart rate reactivity differs by women's psychiatric status: An early marker for developmental risk? Journal of the American Academy of Child \& Adolescent Psychiatry 2004;3:283-290. [PubMed: 15076261]

Narendran S, Nagarathna R, Narendran V, Gunasheela S, Nagendra HR. Efficacy of yoga on pregnancy outcome. Journal of Alternative and Complementary Medicine 2005; 11:237-244.

Neumeister A. Tryptophan depletion, serotonin, and depression: Where do we stand? Psychopharmacology 2003;37:99-115.

Neumeister A, Young T, Stastny J. Implications of genetic research on the role of serotonin type 1A receptor and the serotonin transporter. Psychopharmacology 2004;174:512-524. [PubMed: 15249991]

Obel C, Hedegaard M, Henriksen T, Secher N, Olsen J, Levine S. Stress and salivary cortisol during pregnancy. Psychoneuroendocrinology 2005;30:647-656. [PubMed: 15854781]

O'Connor TG, Caprariello P, Blackmore ER, Gregory AM, Glover V, Fleming P. Prenatal mood disturbance predicts sleep problems in infancy and toddlerhood. Early Human Development 2007;83:451-458. [PubMed: 17008033]

Infant Behav Dev. Author manuscript; available in PMC 2011 December 1. 
Orr ST, Blazer DG, James SA, Reiter JP. Depressive symptoms and indicators of maternal health status during pregnancy. Journal of Women's Health 2007;4:535-542.

Phillips DI. Programming of the stress response: a fundamental mechanism underlying the long-term effects of the fetal environment? Journal of Internal medicine 2007;5:453-60. [PubMed: 17444884]

Porges SW, Doussard-Roosevelt JA, Portales AL, Greenspan SI. Infant regulation of the vagal "brake" predicts child behavior problems: A psychobiological model of social behavior. Development Psychobiology 1996;29:697-712.

Raegan PB, Salsberry PJ. Race and ethnic differences in determinates of preterm birth in the USA: Broadening the social context. Social Science \& Medicine 2005;60:2217-2228. [PubMed: 15748670]

Rice F, Harold GT, Bolvin J, Hay DF, Van den Bree M, Thapar A. Disentangling prenatal and inherited influences in humans with an experimental design. Proceedings of the National Academy of Science of the United States of America 2009;106:2464-2467.

Ruiz RJ, Saade GR, Brown CE, Nelson-Becker C, Tan A, Bishop S, Bukowski R. The effect of acculturation on progesterone/estriol ratios and preterm birth in Hispanics. Obstetrics \& Gynecology 2008;111:309-316. [PubMed: 18238967]

Sandman CA, Glynn L, Dunkel-Shetter C, Wadhwa P, Garite T, Chicz-DeMet A, Hobel C. Elevated maternal cortisol early in pregnancy predicts third trimester levels of placental corticotropin releasing hormone (CRH): priming the placental clock. Peptides 2006;27:1457-1463. [PubMed: 16309788]

Scafidi F, Field T, Wheeden A, Schanberg S, Kuhn C, Symanski R, ...Bandstra ES. Cocaine exposed preterm neonates show behavioral and hormonal differences. Pediatrics 1996;97:851-855. [PubMed: 8657526]

Shea AK, Streiner DL, Fleming A, Kamath MV, Broad K, Steiner M. The effect of depression, anxiety and early life trauma on the cortisol awakening response during pregnancy: Preliminary results. Psychoneuroendocrinology 2007;32:1013-1020. [PubMed: 17855000]

Sjostrom K, Valentin L, Thelin T, Marsal K. Maternal anxiety in late pregnancy and fetal hemodynamics. European Journal of Obstetrics, Gynecology, and Reproductive Biology 1997;74:149-155.

Stewart AL, Dean ML, Gregorich SE, Brawarsky P, Hass JS. Race/ethnicity, socioeconomic status and the health of pregnant women. Journal of Health Psychology 2007;12:285-300. [PubMed: 17284493]

Struder HK, Hollmann W, Platen P, Wostmann R, Ferrauti A, Weber K. Effect of exercise on free tryptophan to branched-chain amino acids ratio and plasma during exercise. Canadian Journal of Applied Psychology 1997;22:280-291.

Suarez EC, Lewis JG, Krishnan RR, Young KH. Enhanced expression of cytokines and chemokines by blood monocytes to in vitro lipopolysaccharide stimulation are associated with hostility and severity of depressive symptoms in healthy women. Psychoneuroendocrinology 2004;29:1119_ 1128. [PubMed: 15219635]

Suri R, Althshuler L, Hellemann G, Burt VK, Aquino A, Mintz J. Effects of antenatal depression and antidepressant treatment on gestational age at birth and risk of preterm birth. The American journal of Psychiatry 2007;164:1206-1213. [PubMed: 17671283]

Tchirikov M, Rybakowski C, Huneke B, Schoder V, Schroder HJ. Umbilical vein blood volume flow rate and umbilical artery pulsatility as venous-arterial index in the prediction of neonatal compromise. Ultrasound Obstetrics and Gynecology 2002;20:580-585.

Teixeira JM, Fisk NM, Glover V. Association between material anxiety in pregnancy and increased uterine artery resistance index: cohort based study. British Medical Journal 1999;318:153-157. [PubMed: 9888905]

Trivedi M. Major depressive disorder: Remission of associated symptoms. Journal of Clinical Psychiatry 2006;67:27-32. [PubMed: 16848674]

Van den Berg BR, Mulder EJ, Mennes M, Glover V. Antenatal maternal anxiety and stress and the neurobehavioral development of the fetus and child: Links and possible mechanisms. A review. Neuroscience \& Biobehavioral Reviews 2005;2:237-258. 
Weinstock M. The potential influence of maternal stress hormones on development and mental health of the offspring. Brain, behavior, and immunity 2005;4:296-308.

Williamson DE, Forbes EE, Dahl RE, Ryan ND. A genetic epidemiologic perspective on comorbidity of depression and anxiety. Child and Adolescent psychiatric Clinics of North America 2005;4:707-726. [PubMed: 16171699]

Wust S, Federenko I, Hellhammer D, Kirschbaum C. Genetic factors, perceived chronic stress, and the free cortisol response to awakening. Psychoneuroendocrinolgy 2000;25:707-720.

Wust S, Federenko I, van Rossum E, Koper J, Hellhammer D. Habituation of cortisol responses to repeated psychosocial stress-further characterization and impact of genetic factors. Psychoneuroendocrinology 2005;30:199-211. [PubMed: 15471617]

Zayas LH, Busch-Rossnagel NA. Pregnant Hispanic women: A mental health study. Families in Society 1992;73:515-521.

Zayas LH, Cunningham M, McKee MD, Jankowski KRB. Depression and negative life events among pregnant African-American and Hispanic women. Women's Health Issues 2002;12:16-22.

Zorrilla EP, Luporsky L, McKay JR, Rosenthal R, Houldin A, Tax A, ...Schmidt K. The relationship of depression and stressors to immunological assays: a meta-analytic review. Brain, Behavior, and Immunity 2001;15:199-226.

Infant Behav Dev. Author manuscript; available in PMC 2011 December 1. 


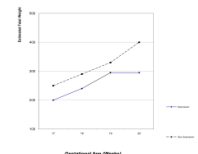

Figure 1.

Estimated weight of fetuses of depressed and nondepressed mothers across early gestation. 


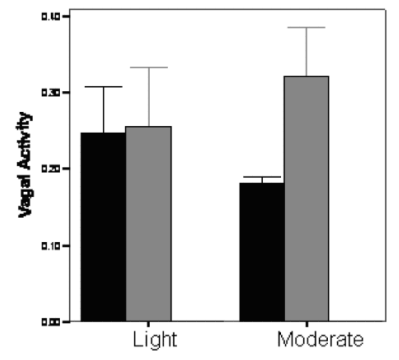

Figure 2.

Vagal Activity before and after light and moderate pressure massage 